\title{
Fatores que influenciam a interação com a interface do Sistema Eletrônico de Editoração de Revistas (SEER)
}

\author{
Suzana Francisca da Rocha \\ Universidade Federal de Goiás - UFG, Brasil \\ Ivette Kafure Muñoz \\ Jayme Leiro Vilan Filho \\ Universidade de Brasília - UnB, Brasil
}

ARTICLE

\begin{abstract}
Resumo
Objetivo. Identificar os aspectos que influenciam a comunicação e mediação da informação entre o usuário autor de artigos e a interface de periódicos científicos eletrônicos que utilizam o SEER.

Método. Delimitaram-se dois periódicos científicos da área da Ciência da Informação - Ciência da Informação e Perspectivas em Ciência da Informação - utilizando-se para a análise da interface o modelo de análise da estrutura de periódicos, as heurísticas e a percepção dos participantes da pesquisa mediante realização de uma tarefa: localizar um artigo específico no periódico.

Resultados. Os resultados mostraram que os participantes são usuários autores frequentes, pois acessam ambos os periódicos tanto para busca de artigos quanto para submeter artigo.

Conclusões. A mediação da informação em relação à interação com interface é satisfatória para os usuáriosautores frequentes, os quais desejam um sistema de busca mais avançado.
\end{abstract}

Palavras-chave:

Interação humano-computador; Mediação e comunicação da informação; Periódico científico eletrônico; Sistema Eletrônico de Editoração de Revistas (SEER); Usabilidade.

Factors that influence the interaction with the interface of the Sistema Eletrônico de Editoração de Revistas (SEER)

\begin{abstract}
Objective. It aims to identify the factors influencing the communication and information mediation between the user author and the electronic journal interfaces using the SEER.

Method. Two scientific journals from the area of Information Science - Ciência da Informação and Perspectivas em Ciência da Informação - were used in a simple task: find a specific article in the journal. The analysis model of the periodical structure, the heuristics and participants perceptions were used in the inferface analysis.

Results. Showed that participants are frequent authors users, because they accessed both journals for search articles and for submissions.

Conclusions. The information mediation of interactions interface is satisfactory for frequent author-users who want a more advanced search system.
\end{abstract}

\section{Keywords}

Communication and mediation of information; Electronic journal; Human-computer interaction; Open Journal Systems (OJS); Usability.

\section{Introdução}

A virtualização dos processos editoriais foi possível graças as Tecnologias de Informação e Comunicação (TIC) que permitiram uma maior dinamização das atividades referentes à submissão, avaliação, distribuição e acesso à informação científica. Esse contexto tecnológico viabilizou a descentralização da exploração comercial da informação científica antes restrita às editoras desse gênero. O cenário tecnológico, o alto custo das publicações 
científicas para o usuário final, e o financiamento de pesquisas proveniente de órgãos governamentais facilitaram a ideia de que a produção científica deveria ser compartilhada pela sociedade. Essa ideia foi concretizada com o movimento de acesso livre/aberto à produção científica, a qual visa uma padronização de protocolos para a disponibilização, de forma gratuita. A exemplo disso, tem-se os repositórios institucionais que reúnem a produção científica de uma instituição - e os periódicos científicos eletrônicos, que por meio de sistemas eletrônicos permitem a editoração de publicações desse tipo.

A motivação da pesquisa se deve, primeiramente, à importância do periódico científico para a ciência - por ser uma ferramenta imprescindível e um canal crucial para a comunicação científica uma vez que confere ao pesquisador prestígio, status, visibilidade, legitima e garante credibilidade à pesquisa (MEADOWS, 1999; MUELLER; 1999). E em segundo plano, a indagação de que, na concepção de sistemas de acesso aberto, os usuários, a acessibilidade e a usabilidade foram considerados a fim de que esse acesso seja pleno. A mediação da informação no meio eletrônico é realizada pela interface (conjuntos de elementos visuais, caracteres, imagens, vídeos e outros) em uma tela de computador que são organizados de forma a facilitar a interação entre o usuário e o sistema. Nesse meio os periódicos possuem um grande potencial de serviços os quais podem ser oferecidas aos seus usuários. Portanto, seria relevante realizar uma pesquisa centrada no usuário a fim de descobrir quem são os usuários desses periódicos, como eles utilizam-no e percebem a interface do mesmo.

Dentre os sistemas pautados na filosofia de acesso livre para publicação de periódicos científicos, como o Sistema de Editoração de Revistas (SEER), o Scientific Information Exchange (SCI), e o Digital Publishing System (Dpubs), apresentaremos o resultado de uma pesquisa com o SEER, utilizando dois dos mais citados periódicos da área da Ciência da Informação: Ciência da Informação e Perspectivas em Ciência da Informação (VILAN FILHO, ARRUDA e PERUCHI, 2012). Os estudos de usabilidade da interface do Sistema Eletrônico de Editoração de Revistas (SEER) (sistema que permite a realização de todo o processo editorial no meio eletrônico) são incipientes. Não foram identificados trabalhos a nível internacional ${ }^{1}$ cujo objetivo fosse estudar a interface do sistema OJS/SEER. Dentre os trabalhos localizados sobre o assunto, podem-se destacar os estudos de usabilidade realizados no SEER por Alvorcem (2010) que analisou a usabilidade sob o aspecto do fluxo do processo editorial e o estudo de Corrêa e Miranda (2012) na seção de Avaliação por pares.

Trata-se de uma pesquisa que tem como objetivo identificar os fatores que influenciam a comunicação e a mediação da informação entre o usuário da informação científica - o autor de artigos (usuário-autor) - e a interface do periódico científico eletrônico que utiliza o SEER na área da Ciência da Informação.

\section{A comunicação na ciência}

Alvim (2003, p. 53) afirma que a comunicação científica "é a troca entre quem gera o conhecimento científico e quem precisa usar esse conhecimento". Mueller e Passos (2000, p. 13) afirmam que a Comunicação Científica é analisada por diversas áreas do conhecimento, mas para a Ciência da Informação o enfoque está direcionado para a produção e uso: os enfoques mais estudados.

As tecnologias de informação e comunicação (TIC), bem como a compreensão de que grande parte da informação científica é produzida via financiamento de impostos - não justificando o preço pago pela aquisição de artigos científicos (MUELLER, 2006) - impulsionaram a disseminação e o acesso à informação científica. Surgem então dois movimentos cujo objetivo era garantir a disponibilização dos trabalhos científicos de forma gratuita, por meio de políticas e estratégias: o OAI (Open Archives Initiative) e Open Access Moviment (FERREIRA, 2008).

Dessas iniciativas surgiram duas vertentes para a disseminação da informação científica no meio eletrônico, ambas sem ônus para o leitor: a via verde, composta pelo armazenamento do conteúdo científico produzido por uma instituição em repositórios eletrônicos; e a via dourada na qual a editoração, avaliação e publicação de artigos científicos ocorre totalmente no meio eletrônico (COSTA, 2006, p. 41). Diversos softwares foram desenvolvidos para a gestão, armazenamento e disponibilização desses conteúdos na internet. No caso da via dourada, um dos sistemas mais utilizado no Brasil (de acordo com Shintaku et. al, 2014) foi desenvolvido no

\footnotetext{
${ }^{1}$ Levantamento realizado na plataforma da EBSCO utilizando os seguintes termos em português e inglês: Periódico científico eletrônico. Interação humano-computador. Usabilidade. Sistema Eletrônico de Editoração de Revistas. SEER.
} 
Canadá, o Open Journal Systems (OJS) ou, Sistema Eletrônico de Editoração de Revistas (SEER) como é mais conhecido no Brasil. O Gráfico 1 ilustra o crescimento do uso desse sistema no Brasil.

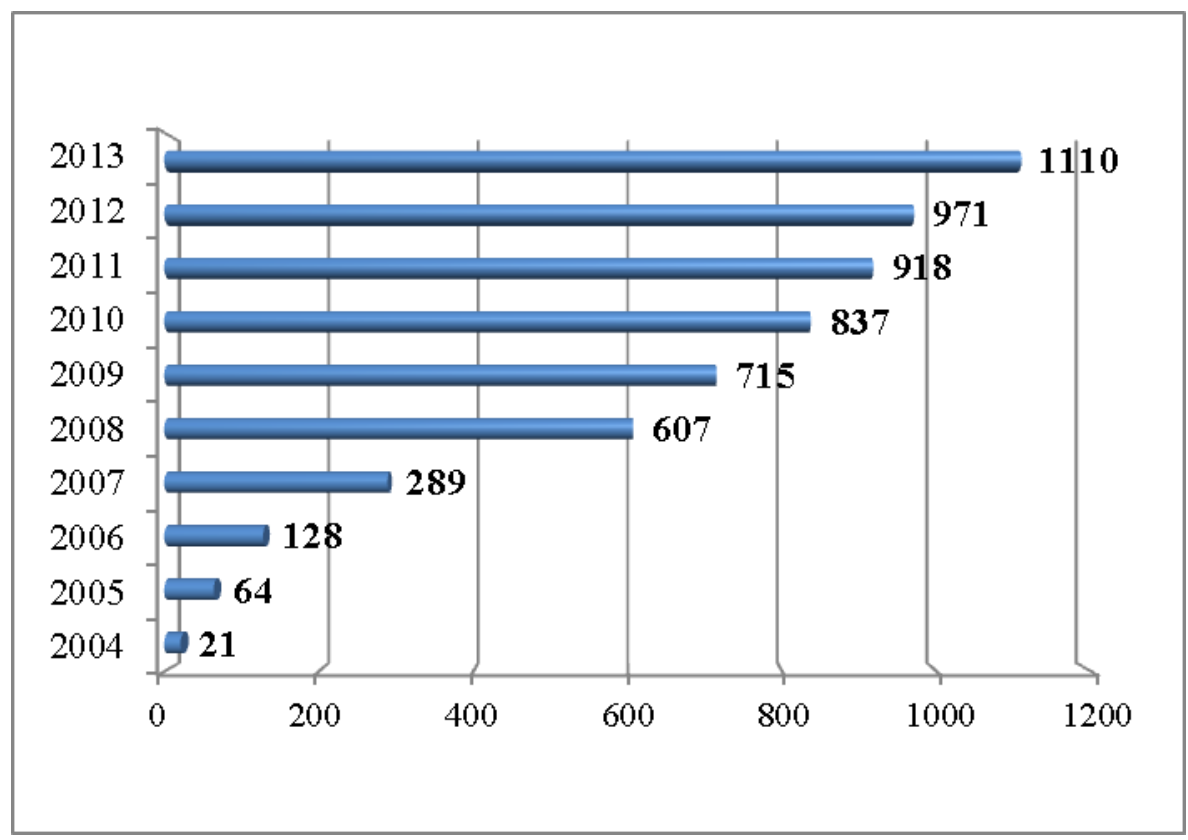

Gráfico 1 - Quantidade de periódicos científicos que utilizam o SEER no Brasil Fonte: Elaborado pelos autores, de acordo com dados do IBICT2.

O sistema OJS/SEER é muito utilizado na América Latina - com 3627 periódicos - e no Brasil - com $1110^{3}$ periódicos cadastrados. A plataforma favoreceu a disseminação da informação científica da América Latina a nível regional e internacional, conferindo maior visibilidade para publicação científica dos países latinos. No Brasil, dos 37 periódicos científicos da área da Ciência da Informação conta com 26 que utilizam o sistema para o gerenciamento e publicação científicos.

\section{A interação humano computador e os estudos de usabilidade}

A inserção e necessidade manipulação de equipamentos eletrônicos com displays, dispositivos com botões, e painéis de controle de voo, criou uma demanda pela compreensão de como o design desses produtos poderiam ser desenvolvidos, levando em consideração, o ser humano e como facilitar seu uso. Diversas áreas são reunidas então a fim de entender o impacto da interação entre seres humanos e computador, como a Psicologia, Sociologia, Antropologia, Design, Ergonomia, Linguística, Semiótica, Computação, dentre outras (HEWETT, et. al., 1992, p. 8). A Figura 1 apresenta os objetos de estudo da interação humano computador (IHC), em que diversos fatores são considerados para a análise do indivíduo enquanto usuário de um dado sistema/máquina: contexto de uso, o tipo de interação envolvida, as características humanas, a interface dos sistemas computacionais bem como os processos de desenvolvimento do sistema (BARBOSA; SILVA, 2010, p. 10-11).

\footnotetext{
${ }^{2}$ Dados retirados do portal do SEER, o qual apresenta a quantidade de revistas cadastradas por ano. Disponível em: http://seer.IBICT.br/index.php?option=com mtree\&task=listcats\&cat id=122\&ltemid=109

${ }^{3}$ Informações retiradas no site http://seer. IBICT.br/index.php?option=com mtree\&ltemid=109 em novembro de 2015.
} 


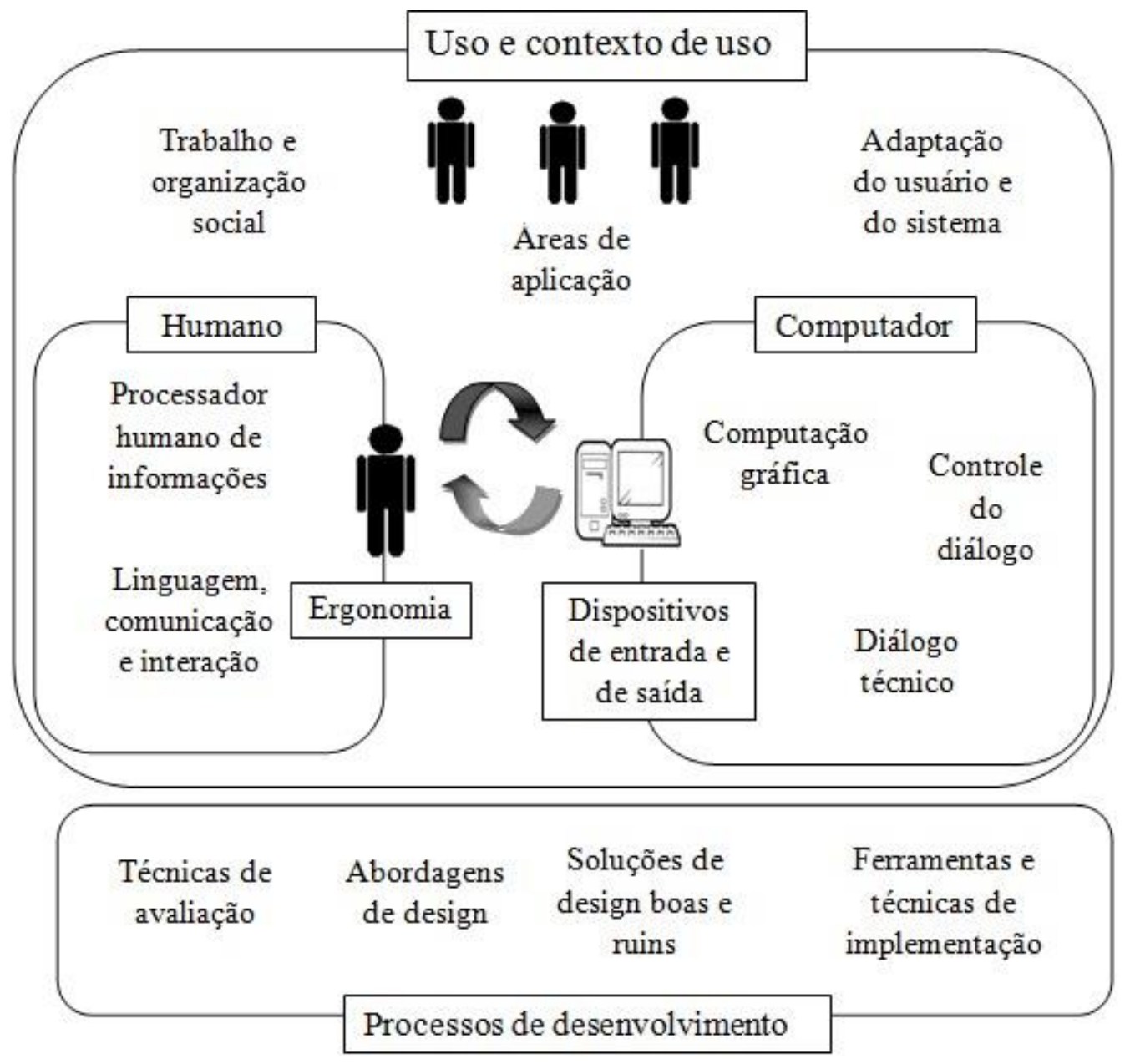

Figura 1 - Objetos de estudo em IHC (adaptado de Hewett, et al., 1992)

Fonte: Barbosa; Silva, 2010, p. 10.

Dentre as formas existentes de estudar a IHC, ressaltamos duas: a usabilidade que "[...] mede até que ponto um produto de informação, um sistema de informação, um serviço de informação ou uma informação se prestam ao uso" (LE COADIC, 2004, p. 49); e o teste empírico com os usuários, que visa identificar problemas de recorrentes de usabilidade diretamente com quem utiliza o sistema (DIAS, 2006).

A questão da localização da informação ganhou mais um componente: a interface que fica entre os sistemas de informação e o usuário. Até então, essa mediação era realizada por um bibliotecário de referência ou pelos catálogos das bibliotecas, além do que muitas vezes a produção científica - como teses e dissertações ficavam restritas ao local em que foram produzidas. O contexto proporcionado pelo acesso aberto e as TIC eliminaram essa barreira geográfica, mas ao mesmo tempo "exigiram" que a autonomia desses usuários satisfizesse suas necessidades informacionais.

\section{Metodologia}

Classifica-se a presente pesquisa como um levantamento descritivo com abordagem qualitativa e quantitativa de natureza aplicada. A fim de delimitar o contexto da pesquisa optou-se realizar a pesquisa com uma única área do conhecimento, Ciência da Informação, com o intuito de viabilizar uma análise mais detalhada entre as variáveis: usuário $X$ área do conhecimento $X$ hábitos de pesquisa $X$ interação com o periódico on-line.

Para a realização da pesquisa, utilizou-se os dois periódicos mais citados na área da Ciência da Informação entre os anos de 2009 e 2010 que usam o SEER (VILAN FILHO, ARRUDA; PERUCCHI, 2012): periódicos 
Ciência da Informação e Perspectivas em Ciência da Informação. Foram aplicados questionários aos autores que publicaram nos referidos periódicos por meio do Google Docs e dos endereços eletrônicos disponibilizados na plataforma Lattes de cada autor. O questionário foi elaborado mediante o embasamento com as pesquisas de Kafure (2004) e Monteiro (2005), as quais desenvolveram os trabalhos visando conhecer a interação entre usuário e a interface. O mesmo estava organizado em quatro blocos, composto por vinte e duas questões, com perguntas abertas e fechadas: o primeiro bloco teve como objetivo a coleta de informações sobre o perfil dos participantes; o segundo bloco visou conhecer o perfil de pesquisa dos participantes; o terceiro bloco teve como objetivo conhecer como ocorre a interação entre os usuários e os periódicos científicos eletrônicos "Ciência da Informação" e "Perspectivas em Ciência da Informação"; e o quarto identificou a interface cuja localização da informação foi mais fácil.

Propôs-se localizar dois artigos: 1) "Elitismo na literatura sobre a produtividade de autores", de autoria de Ruben Urbizagastegui Alvarado, publicado no periódico "Ciência da Informação" volume 38, número 2 de 2009, e 2) "Citações presentes em teses e perfis de pesquisadores: fontes de indícios para se estudar a área da educação física”, das autoras Ivone Job e Lídia Alvarenga, publicado no periódico Perspectivas em Ciência da Informação, volume 13, número 03, Setembro - Dezembro de 2008. A partir disso, os participantes responderam:

- Como conseguiram localizar o artigo, descrevendo as etapas realizadas;

- Se perceberam a possibilidade de encontrar o mesmo artigo por outras alternativas;

- Se durante o processo detectaram alguma dificuldade em localizar o artigo;

A estrutura dos dois periódicos foi caracterizada mediante uso do modelo de avaliação de periódico de Sarmento e Souza (2002) as heurísticas de usabilidade de Nielsen (1993) e Dias (2006).

O universo da pesquisa foi composto por 361 autores de ambos periódicos. Desse total, um autor tinha publicação póstuma; não foram localizados o currículo Lattes de 20 autores; e, dentre os resultados fornecidos pelo Lattes não foi possível identificar o currículo de 12 autores (vários resultados do mesmo nome). Sendo enviados e-mails para 319 autores. Desses, apenas 80 responderam ao questionário.

\section{Resultados}

\subsection{Perfil dos participantes}

Os 80 usuários-autores participantes da pesquisa eram homens e mulheres, brasileiros, a maioria docentes do ensino superior/pesquisadores, e bibliotecários. A faixa etária desses usuários-autores foi bem homogênea, sendo que a maioria possui entre 31 e 45 anos. Eles utilizam livros e artigos científicos como fonte de informação, e afirmaram conhecer os periódicos científicos da área, os quais utilizam somente no meio digital. Os participantes utilizam os periódicos semanalmente de casa e dificilmente os utilizam na biblioteca. Constatouse também que os docentes e pesquisadores tenderam a acessar a informação científica por meio das bases de dados, enquanto que os estudantes da pós-graduação tenderam a utilizar buscadores (como Google e Yahoo) para essa finalidade. Os usuários-autores disseram que a localização do artigo nos periódicos científicos foi fácil principalmente devido ao uso constante dessas ferramentas.

Os participantes que responderam que a localização de artigos não é fácil (13\%), justificaram não conhecerem algumas fontes de informação, como bases de dados, o que pode explicar o gráfico anterior no qual 37\% dos participantes utilizam os buscadores para os periódicos científicos. Citaram problemas relacionados à indexação dos artigos, como problema semântico nas palavras-chave e recuperam artigos que não refletem o assunto desejado. Outra justificativa é que os sistemas de gerenciamento dos periódicos ficam fora do ar, impossibilitando a busca pela informação científica. Um respondente afirmou que os artigos nacionais são mais fáceis de localizar do que os internacionais (algumas bases de dados disponibilizam apenas as referências, ex.: LISA). A última dificuldade apontada é quanto a interface, que em alguns, casos intefere negativamente na localização do artigo buscado. 


\subsection{Análise da interface do periódico de acordo com as heurísticas de Nielsen e Dias}

Embora utilizem versões diferentes do SEER, os periódicos apresentam similaridades, facilitando o uso de outros periódicos que utilizam a mesma plataforma. Em ambos os periódicos o sistema de organização, quanto ao esquema, classifica-se como exato por localização, enquanto a estrutura é hierárquica. A respeito da navegação, classifica-se como local e ad hoc.

A interface apresenta elementos que possibilitam a localização do usuário durante o acesso a todas as possibilidades da plataforma, pois os menus estão presentes em todas as páginas do periódico. Podemos destacar que no periódico Ciência da Informação, cuja interface é ilustrada na Figura 2, a única ocorrência em que os menus não estão disponíveis é no layout de leitura, pois a visualização é por meio de uma página de PDF.

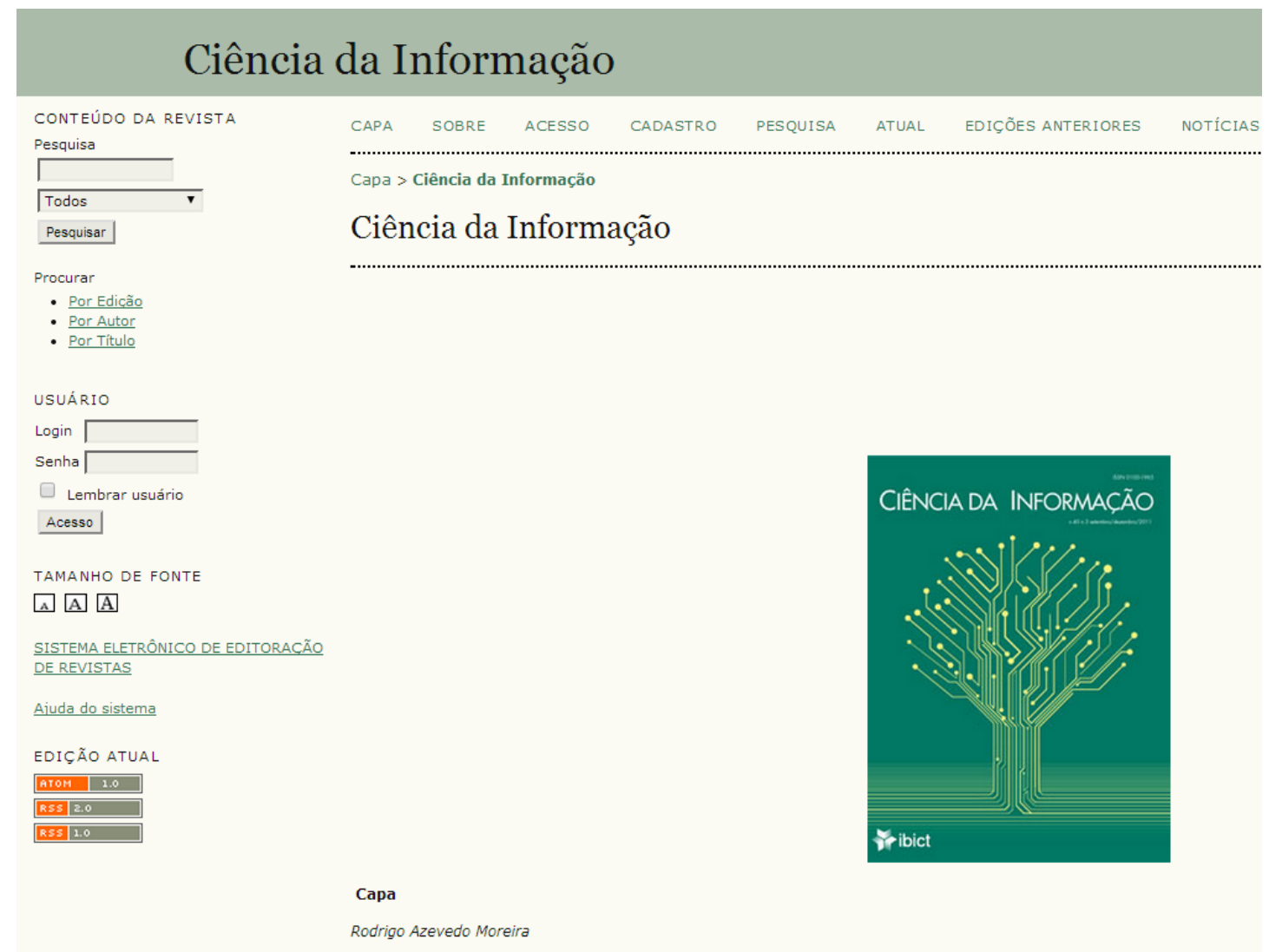

Figura 2 - Interface do periódico Ciência da Informação

Fonte: IBICT

Entre o menu superior e o título da informação em destaque da página inicial há um link, indicando a página em que o usuário se encontra. A plataforma não permite ao usuário saber as páginas visitadas anteriormente por ele, ou seja, não apresenta mapa de navegação de todo o percurso realizado.

\subsection{Interação com os periódicos}

Quanto ao acesso aos periódicos científicos, os usuários-autores declararam utilizar "Ciência da Informação" ocasionalmente para consultas acadêmicas e submissão de artigos, e que acessaram "Perspectivas em Ciência da Informação", ocasionalmente para consultas acadêmicas.

O formulário de pesquisa apresentou uma tarefa na qual o respondente localizou um artigo específico - indicado no formulário - em ambos os periódicos. A partir disso o participante relatou como conseguiu localizar a informação e indicou eventuais diferenças de busca entre os dois periódicos, mediante sua percepção. A interação foi considerada boa por $85 \%$ dos participantes, pois conseguiram realizar a tarefa solicitada e não 
relataram dificuldades para encontrar o artigo. A facilidade dos usuários na utilização do sistema pode ser explicada pela maioria consultar frequentemente os periódicos, conforme mencionado durante as respostas.

A estratégia mais utilizada em ambos periódicos foi o uso da caixa de busca na página principal, com a localização pelo título, seguida pela busca pelo nome do autor, embora existam outras formas de localizar o periódico: edições anteriores, busca avançada e índice de autor.

Os participantes apontaram alguns itens os quais consideram problemas na interface. No caso do periódico "Ciência da Informação" quanto a localização dos menus, a localização da caixa de busca na página inicial e a "busca" pela seção edições anteriores. No periódico "Perspectivas em Ciência da Informação" foram apontados problemas quanto a localização da caixa de busca, e quanto ao uso da barra de rolagem na vertical.

Quanto aos pontos positivos os usuários-autores consideraram que o periódico "Ciência da Informação" possuía uma interface mais fácil de usar, por não apresentar excesso de informação na página inicial, enquanto que outros consideraram o periódico "Perspectivas em Ciência da informação" mais agradável, com layout mais dinâmico, cuja interface está representada na Figura 3.

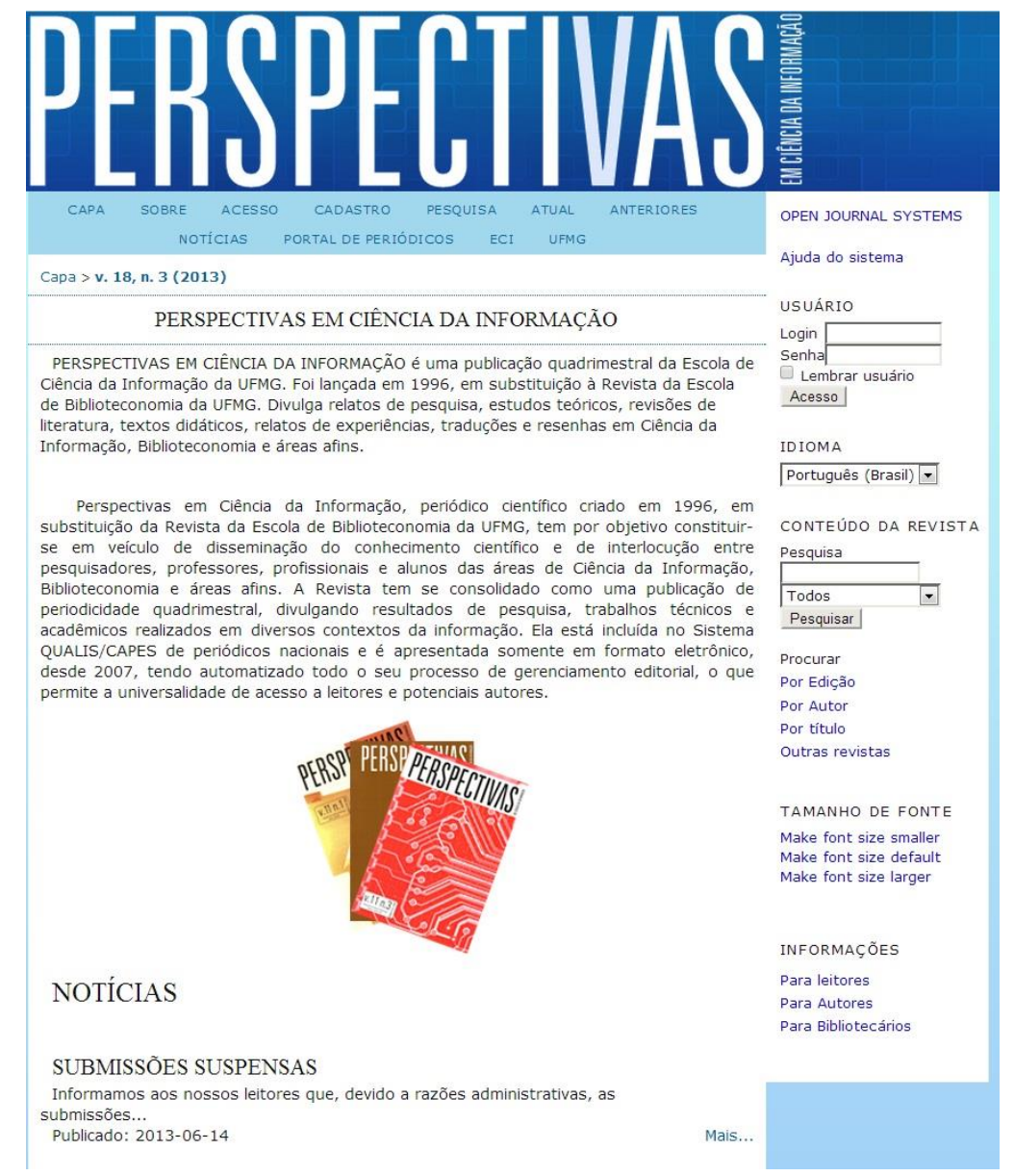

Figura 3 - Interface do periódico Perspectivas em Ciência da Informação

Fonte: UFMG, Escola de Ciência da Informação.

Os usuários-autores foram consultados quanto ao que alterariam na página do periódico para melhorar a navegação. Eles esboçaram alterações quanto a disposição dos menus e caixa de pesquisa, a fim de evidenciar os elementos de busca no periódico. A necessidade mais expressiva foi quanto ao mecanismo de busca do sistema: eles gostariam de um sistema que permita uma busca mais avançada e dinâmica. Ou seja, a plataforma ofereceu aos usuários duas opções de busca pela inserção de termos: a busca na página inicial que permite uma busca simples por autor, título, assunto ou "todos os campos"; e a busca avançada, presente no menu superior que possibilita a realização da busca a partir da entrada -combinação - de todos os termos. Pelos relatos dos participantes, eles querem procurar um artigo por meio da combinação de vários elementos em uma mesma caixa de busca e que a mesma esteja de fácil acesso - na página principal. 


\section{Conclusões}

Apesar do domínio da ferramenta por parte dos usuários e pela facilidade relatada por eles em utilizá-la, algumas sugestões foram indicadas pelos mesmos para tornar o uso da interface mais intuitiva. Quanto a interface, as indicações mais comentadas foram quanto a evidência dos elementos de busca dos artigos: edições anteriores, caixa de busca da página inicial e busca avançada.

Entretanto, a sugestão mais evidenciada durante as respostas foi em relação aos comandos permitidos pelo algoritmo de busca que a plataforma utiliza. Enquanto usuários experientes, conhecedores das funcionalidades do sistema, eles desejam um mecanismo de busca mais avançado que permita pesquisas mais elaboradas a partir de poucos elementos.

De acordo com os usuários-autores, participantes da pesquisa, o fator que influencia a comunicação e mediação da informação entre os mesmos e a interface dos periódicos científicos eletrônicos é a localização da caixa de pesquisa na página inicial e o sistema de busca avançada - o qual deveria oferecer, segundo os usuáriosautores - mais elementos de combinação de busca.

Outro fator que interfere na comunicação e mediação da informação na interface do periódico científico é a categoria do usuário - se são experientes, em potencial ou esporádicos, bem como se são docentes, pesquisadores, estudantes da graduação ou pós-graduação -, que reflete em como buscam, localizam e utilizam a informação científica.

Os resultados do estudo, juntamente com as leituras realizadas para a composição do trabalho levaram a conclusão de que os seguintes estudos com periódicos científicos eletrônicos são relevantes para a área:

a) Estudo com interface do OJS/SEER destinado a pessoas portadoras de deficiência visual. Esse estudo seria voltado para a acessibilidade da plataforma, visto as TIC facilitaram o acesso à informação de pessoas não videntes. O objetivo seria identificar os fatores da interface que interferem na localização da informação para esse tipo de usuário.

b) Analisar os mecanismos de busca utilizados no sistema OJS/SEER. Alguns respondentes dessa pesquisa concentraram os seus esforços em criticar essa parte da plataforma.

c) Verificar se os usuários em potencial (que não utilizam os periódicos, mas possuem grande chance de utilizá-los) consideram a interface de fácil navegação e qual estratégia de localização do artigo seria utilizado.

Tais estudos poderão trazer mais elementos sobre o tema desta pesquisa. 


\section{Referências}

ALVIM, Paulo César R. Comunicação da ciência. In: DUARTE, Jorge; BARROS, Antônio Teixeira de (ed.). Comunicação para a ciência, ciência para a comunicação. Brasília: Embrapa Informação Tecnológica, 2003. p. 47-66

BARBOSA, Simone Diniz Junqueira; SILVA, Bruno Santana da. Interação humano-computador. Rio de Janeiro: Elsevier, 2010. 384 p.

COSTA, Sely M. S. Filosofia aberta, modelos de negócios e agências de fomento: elementos essenciais sobre a discussão sobre o acesso aberto à informação científica. Ciência da Informação, Brasília, v. 35, n. 2, p. 39-50, mai./ago. 2006. Disponível em: <http://www.scielo.br/pdf/ci/v35n2/a05v35n2.pdf>. Acesso em: 08 out. 2012.

DIAS, Cláudia. Usabilidade na web: criando portais mais acessíveis. 2. ed. Rio de Janeiro: Alta Books, 2006.296 p.

FERREIRA, Sueli Mara Soares Pinto. Repositórios versus revistas científicas: convergências e convivências. In: FERREIRA Sueli Mara Soares Pinto; TARGINO, Maria das Graças. (Orgs.). Mais sobre revistas científicas: em foco a gestão. São Paulo: Editora Senac/Cengage learning, 2008. p. 111-137.

HEWETT, Thomas T.; BAECKER, Ronald; CARD, Stuart; CAREY, Tom; GASER, Jean; MANTEI, Marilyn; PERLMAN, Gary; STRONG, Gary; VERPLANK, Willian. Curricula for human-computer interaction. Nova York: [s.n.], 1992/1996. Relatório da Association for Computing Machinery e Special Interest Group on Computer Human Interaction. Disponível em: <http://old.sigchi.org/cdg/>. Acesso em: 27 set. 2012.

LE COADIC, Yves-François. A ciência da informação. 2. ed. Brasília: Briquet de Lemos Livros, 2004. 124p.

MUELLER, Suzana Pinheiro Machado. Comunicação científica e o movimento de acesso livre ao conhecimento. Ciência da Informação, Brasília, v. 35, n. 2, p. 27-38, mai./ago. 2006. Disponível em: <http://www.scielo.br/pdf/ci/v35n2/a04v35n2.pdf>. Acesso em: 08 abr. 2012

MUELLER, Suzana Pinheiro Machado; PASSOS, Edilenice Jovelina Lima (Orgs.). Comunicação científica. Brasília, UnB: 2000. 144 p. (Estudos avançados em Ciência da Informação, v. 1).

NIELSEN, Jakob. Usability engineering. Boston: Academic Press, 1993. 362 p.

SARMENTO E SOUZA, Maria Fernanda. Periódicos científicos eletrônicos: apresentação de modelo para análise de estrutura. 2002. 133 f. Dissertação (Mestrado em Ciência da Informação) - Faculdade de Filosofia e Ciências, Universidade Estadual Paulista, Marília, 2002. Disponível em: <http://www.cpap.embrapa.br/teses/online/DST10.pdf>. Acesso em: 17 out. 2013.

SHINTAKU, Milton; DE BRITO, Ronnie Fagundes; NETO, Sílvio Carvalho. A avaliação dos portais de revistas brasileiros implementados com o SEER/OJS por meio do levantamento da indexação pelo Latindex e SciELO. Informação \& Sociedade: Estudos, v. 24, n. 2, 2014. Disponível em: <http://www.biblionline.ufpb.br/ojs2/index.php/ies/article/view/18671>. Acesso em: 26 abr. 2015.

VILAN FILHO, Jayme Leiro; ARRUDA, Raíza Veloso; PERUCCHI, Valmira. Análise das citações aos periódicos científicos brasileiros das áreas de informação. Em Questão, Porto Alegre, edição especial, p. 115-127, dez. 2012.

\section{Notas}

Artigo oriundo de dissertação de mestrado defendido no PPGCINF/UnB em 25 de fevereiro de 2014 


\section{Dados dos autores}

\section{Suzana Francisca da Rocha}

Mestre em Ciência da Informação pelo Programa de Pós-Graduação em Ciência da Informação da Universidade de Brasília (UnB) - 2014. Graduada em Biblioteconomia pela Universidade Federal de Goiás (UFG) - 2011. Atua como bibliotecária e professora na Faculdade de Goiânia (Anhanguera Educacional). Professora substituta na Universidade Federal de Goiás, ministrando as disciplinas: serviço de referência e informação e pesquisa e normalização documentária.

rocha.suzanafr@gmail.com

\section{Ivette Kafure Muñoz}

Doutora em Ciência da Informação, Universidade de Brasília. Mestre em Informática, Universidade Federal de Campina Grande. Especializada em Práticas Audiovisuais, Universidade del Valle, Cali, Colômbia. Graduada em Engenharia de Sistemas, Universidade Autônoma de Manizales, Manizales, Colômbia. Atualmente é professora na Universidade de Brasília na Faculdade de Ciência da Informação (FCl/UnB). Atua principalmente nos seguintes temas: estudo de usuários, ergonomia cognitiva, fator emocional, usabilidade e acessibilidade da informação, experiência do usuário, tecnologia assistiva e educacional.

ivettekead@gmail.com

\section{Jayme Leiro Vilan Filho}

Professor da UnB (1996-), Doutor em Ciência da Informação, Mestre em Biblioteconomia e Documentação com graduação em Processamento de Dados (1979-1982). Líder do Grupo de Pesquisa Comunicação Científica (PPGCInf/UnB) atuando em atividades relacionadas com produção, colaboração, análise de citação e fluxo da informação científica nas áreas de informação no Brasil. Editor da base de dados bibliográfica ABCDM (artigos e trabalhos científicos brasileiros das áreas de informação). Coordenador de Extensão da FCl de 2010-2011 e de 2014-2015, tendo coordenado e ministrado cursos de extensão (1999-2006). Atuou como analista de sistemas na BINAGRI/CENAGRI (1982-1984), SERPRO (1984-1985) e IBICT/CNPq (1985-1996).

jleiro@unb.br

Recebido - Received: 2016-03-14

Aceitado - Accepted: 2017-03-22

\section{$(\mathrm{cc}) \mathrm{BY}$}

This work is licensed under a Creative Commons Attribution 4.0

United States License.

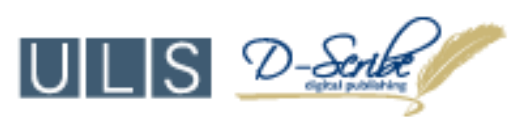

This journal is published by the University Library System of the University of Pittsburgh as part of its D-Scribe Digital Publishing Program and is cosponsored by the University of Pittsburgh Press. 